\title{
Efficacy of growth hormone therapy in adults with childhood-onset growth hormone deficiency
}

Ja Hye Kim, MD, Ja Hyang Cho, MD, Han-Wook Yoo, MD, PhD, Jin-Ho Choi, MD, PhD

Department of Pediatrics, Asan Medical Center Children's Hospital, University of Ulsan College of Medicine, Seoul, Korea
Purpose: Growth hormone (GH) plays a key role in the regulation of body composition, lipid metabolism, and quality of life in adults with GH deficiency (GHD). This study investigated changes in laboratory findings and body composition after $\mathrm{GH}$ recommencement for adult GHD and analyzed correlation between $\mathrm{GH}$ interruption period and endocrine or anthropometric parameters.

Methods: A total of 45 patients ( 17 females and 28 males) diagnosed with childhood-onset GHD (CO-GHD) were investigated and all patients had organic brain lesions. Patients diagnosed CO-GHD were retested to confirm adult GHD at age 20.4 \pm 5.0 years (18.0-32.1 years). Recombinant human GH was administered at a dose of $0.44 \mathrm{mg} /$ day. Clinical and laboratory parameters such as weight, height, body mass index (BMI), serum insulin-like growth factor 1 (IGF-1), serum total cholesterol, high-density lipoprotein (HDL) cholesterol, low-density lipoprotein (LDL) cholesterol, and triglyceride levels, were compared between baseline and 12 months after treatment using paired $t$-test. In addition, correlation between GH interruption period and clinical parameters including BMI, lipid profile, IGF-1, and IGFBP-3, was analyzed.

Results: Of 45 patients, 33 patients had GH interruption period of $4.3 \pm 3.6$ years (0.7-12.5 years). Serum HDL-cholesterol level increased significantly, whereas LDLcholesterol decreased after 1 year of GH replacement therapy. However, body weight and BMI showed no significant changes after 1 year of GH replacement therapy. There were no significant correlations between GH interruption period and lipid profile or anthropometric parameters.

Conclusion: BMI and body weight were not affected by $\mathrm{GH}$ replacement. However, $\mathrm{GH}$ replacement in adults with GHD offers benefits in lipid metabolism.

Keywords: Pituitary dwarfism, Body mass index, Cholesterol, Insulin-like growth factor 1

\section{Introduction}

The optimal management of growth hormone deficiency (GHD) during childhood is to promote linear growth and to achieve adult height within the target height range. Adults with GHD have been reported to have reduced lean body mass, bone mineral density (BMD) and increased cardiovascular risk ${ }^{1)}$. The goal of growth hormone (GH) replacement in adulthood is to improve body composition, to reduce cardiovascular risk factors, and to improve quality of life ${ }^{2)}$.

Despite growing evidence on benefits of GH therapy in adults with GHD, there are still obstacles for GH therapy due to high cost, necessities for daily injections, and lack of awareness regarding its indication. The transition period is arbitrarily defined as the period of adolescence after linear growth is completed when GH replacement is required due to ongoing $\mathrm{GHD}^{3}$. Continuation of GH therapy without interruption is recommended
Address for correspondence: Jin-Ho Choi, MD, PhD

Department of Pediatrics, Asan Medical Center Children's

Hospital, University of Ulsan College of Medicine, 88 Olympic-ro 43-gil,

Songpa-gu, Seoul 138-736, Korea

Tel: +82-2-3010-3991

Fax: +82-2-473-3725

E-mail: jhc@amc.seoul.kr 
for adolescents transitioning to adulthood by guidelines of American Association of Clinical Endocrinologists and The Endocrine Society ${ }^{4,5)}$. However, the national health insurance of Korea covers the cost for GH therapy until females and males reach their final height of 150 and $160 \mathrm{~cm}$, and resume after age 18 years. Therefore, most patients with GHD are obligated to have interruption period of GH replacement. In addition, GH stimulation testing is required before restart of GH therapy even in the presence of multiple pituitary hormone deficiency with structural abnormalities in the hypothalamus or pituitary gland.

This study investigated changes in laboratory findings and body composition after a year of GH replacement in adults with childhood-onset GHD (CO-GHD). In addition, we analyzed correlation between $\mathrm{GH}$ interruption period and endocrine or anthropometric parameters.

\section{Materials and methods}

\section{Subjects}

A total of 45 patients (17 females and 28 males) diagnosed with CO-GHD were included. Adult GHD was defined by (1) patients older than or equal to 18 years of age; (2) growth velocity less than $2 \mathrm{~cm}$ per year; and (3) peak GH level by insulin tolerance test less than $5 \mathrm{ng} / \mathrm{mL}$. All patients had structural abnormalities including brain tumor, pituitary hypoplasia, ectopic neurohypophysis, and pituitary stalk interruption syndrome (Table 1). Craniopharyngioma was the most frequent cause of GHD (40\%). GH interruption period was defined by the duration between endpoint of $\mathrm{GH}$ replacement for COGHD and treatment restart time for adult GHD. Among 45 patients, 33 patients had GH interruption period.

\section{Methods}

Recombinant human GH was administered at a dose of $0.44 \mathrm{mg} /$ day for 6 days a week. Clinical parameters including anthropometric findings, and laboratory results were collected retrospectively by medical charts review. Anthropometric findings including weight, height, body mass index (BMI, kg/ $\mathrm{m}^{2}$ ), and laboratory findings including lipid profile, insulin-like growth factor-1 (IGF-1), and IGF binding protein-3 (IGFBP-3) were collected at baseline and one year after $\mathrm{GH}$ replacement, and were compared before and after GH therapy. Correlation between GH interruption period and clinical parameters including BMI, lipid profile, IGF-1, and IGFBP-3, was analyzed.

\section{Statistical analyses}

Data are presented as mean \pm standard deviation which is normally distributed. Statistical analyses were performed using IBM SPSS ver. 21.0 (IBM Co., Armonk, NY, USA). Paired $t$-test was used to compare the values before and after GH treatment. Relationship between GH interruption period and endocrine parameters was analyzed by Pearson correlation analysis. $P$-values $<0.05$ were considered statistically significant.

\section{Results}

\section{Clinical characteristics of adults with GHD}

One patient (2.2\%) had isolated GHD, and 3 patients $(6.7 \%)$ showed GHD with one more pituitary hormone deficiency. Four patients $(8.9 \%)$ had GHD with two more pituitary hormone deficiency. Thirty seven patients (82.2\%) revealed more than three pituitary hormone deficiency other than GHD. The average age at restart of GH treatment for adult GHD was $20.4 \pm 5.0$ years (18.0-32.1 years). Final adult height SDS at retest was $-0.93 \pm 1.55$. Mean dose of $\mathrm{GH}$ was $7.0 \pm 1.6 \mu \mathrm{g} / \mathrm{kg} /$ day $(3.9-$ $10.6 \mu \mathrm{g} / \mathrm{kg} /$ day).

Body weight and BMI showed no significant changes after one year of GH replacement therapy. However, serum IGF-1 and IGFBP-3 levels increased significantly after one year of GH replacement therapy. Total cholesterol and triglyceride levels displayed no significant changes, but, serum HDL-cholesterol increased and LDL-cholesterol and LDL/HDL-cholesterol ratio decreased significantly after one year with GH replacement therapy (Table 2).

\section{Endocrine consequences after $\mathrm{GH}$ interruption}

Of 45 patients, 33 patients had GH interruption period of $4.3 \pm 3.6$ years $(0.7-12.5$ years). Mean age at initiation of $\mathrm{GH}$ treatment was $12.5 \pm 2.7$ years, and mean age of recommencing $\mathrm{GH}$ treatment as an adult was $20.1 \pm 2.7$ years. GH interruption period was inversely related with IGF-1 and IGFBP-3. However, there was no significant correlation between the duration of $\mathrm{GH}$ interruption and lipid profile or BMI (Table 3).

\section{Discussion}

This study demonstrated that GH replacement in adult GHD had a positive effect on lipid profile; serum LDL-cholesterol level

\begin{tabular}{|c|c|}
\hline Etiology & No. (\%) \\
\hline Craniopharyngioma & $18(40)$ \\
\hline Germinoma & $14(31.1)$ \\
\hline Pituitary adenoma & $3(6.7)$ \\
\hline Brainstem glioma & $1(2.2)$ \\
\hline Nasopharyngeal cancer & $1(2.2)$ \\
\hline Astrocytoma & $1(2.2)$ \\
\hline Pituitary hypoplasia & $1(2.2)$ \\
\hline Pituitary stalk interruption syndrome & $3(6.7)$ \\
\hline Rathke cleft cyst & $2(4.4)$ \\
\hline Ectopic neurohypophysis & $1(2.2)$ \\
\hline Total & $45(100)$ \\
\hline
\end{tabular}


Table 2. Changes in clinical and biochemical parameters after GH replacement

\begin{tabular}{lccc}
\hline Variable & Baseline & After 1 year & $P$-value \\
\hline Weight $(\mathrm{kg})$ & $66.5 \pm 17.0$ & $67.4 \pm 18.4$ & 0.103 \\
Body mass index $\left(\mathrm{kg} / \mathrm{m}^{2}\right)$ & $24.6 \pm 4.5$ & $24.7 \pm 5.0$ & 0.757 \\
IGF-1 $(\mathrm{ng} / \mathrm{mL})$ & $65.1 \pm 54.8$ & $191.4 \pm 126.1$ & $<0.001^{\mathrm{a})}$ \\
IGFB-3 $(\mathrm{ng} / \mathrm{mL})$ & $2,222.3 \pm 799.8$ & $2,939.1 \pm 1,294.8$ & $0.002^{\mathrm{a})}$ \\
Total cholesterol $(\mathrm{mg} / \mathrm{dL})$ & $191.4 \pm 38.8$ & $187.3 \pm 52.7$ & 0.460 \\
Triglyceride $(\mathrm{mg} / \mathrm{dL})$ & $142.4 \pm 83.7$ & $164.8 \pm 121.7$ & 0.173 \\
HDL-cholesterol $(\mathrm{mg} / \mathrm{dL})$ & $42.9 \pm 15.6$ & $51.8 \pm 17.7$ & $<0.001^{\mathrm{a})}$ \\
LDL-cholesterol $(\mathrm{mg} / \mathrm{dL})$ & $122.4 \pm 39.7$ & $111.7 \pm 43.2$ & $0.049^{\mathrm{a})}$ \\
LDL/HDL-cholesterol ratio & $3.3 \pm 1.6$ & $2.3 \pm 0.9$ & $<0.001^{\mathrm{a})}$ \\
\hline Values are & & &
\end{tabular}

Values are presented as mean \pm standard deviation.

GH, growth hormone; IGF-1, insulin-like growth factor-1; IGFBP-3, IGF binding protein-3; HDL, high-density lipoprotein; LDL, low-density lipoprotein.

a) Statistically significant.

Table 3. Correlation of GH interruption period and clinical parameters

\begin{tabular}{lcc}
\hline Variable & $r$ & $P$-value \\
\hline Body mass index $\left(\mathrm{kg} / \mathrm{m}^{2}\right)$ & -0.03 & 0.840 \\
Total cholesterol $(\mathrm{mg} / \mathrm{dL})$ & -0.15 & 0.399 \\
Triglyceride $(\mathrm{mg} / \mathrm{dL})$ & 0.01 & 0.946 \\
HDL-cholesterol $(\mathrm{mg} / \mathrm{dL})$ & 0.22 & 0.227 \\
LDL-cholesterol $(\mathrm{mg} / \mathrm{dL})$ & -0.28 & 0.115 \\
IGF-1 $(\mathrm{ng} / \mathrm{mL})$ & -0.40 & $0.022^{\mathrm{a})}$ \\
IGFBP-3 $(\mathrm{ng} / \mathrm{mL})$ & -0.40 & $0.022^{\mathrm{a})}$
\end{tabular}

$\mathrm{GH}$, growth hormone; $\mathrm{HDL}$, high-density lipoprotein; LDL, lowdensity lipoprotein; IGF-1, insulin-like growth factor-1; IGFBP-3, IGF binding protein-3.

${ }^{\text {a) }}$ Statistically significant.

significantly decreased, whereas HDL-cholesterol increased. Although 41 patients had hypothyroidism which could affect on lipid metabolism ${ }^{6}$, most patients with central hypothyroidism were adequately supplemented with L-thyroxine. Similar to previous meta-analysis ${ }^{7}$, GH treatment significantly reduced LDL-cholesterol and LDL/HDL-cholesterol ratio. However, body weight and BMI did not show significant change. Previous studies showed that GH therapy is effective in increasing lean body mass, decreasing fat mass, and decreasing central adiposity $^{2}$. However, body composition was not checked in the present study. Since central adiposity and increased fat mass may contribute to the increased incidence of cardiovascular mortality, dual x-ray absorptiometry should be used to quantify changes in body composition ${ }^{8)}$.

GHD is also associated with reduced BMD and high risk of osteoporosis and fractures. Meta-analysis has shown significant increase in lumbar spine and femur neck BMD by GH replacement therapy in adults with GHD, especially in males" ${ }^{9}$. Recent prospective study reported bone remodeling marker including osteocalcin and carboxy-terminal collagen crosslinks increased during $\mathrm{GH}$ replacement ${ }^{10)}$. Although our study did not evaluate $\mathrm{BMD}$, it is required to evaluate fracture risks in adults with GHD.

Re-evaluation of GH status is recommended after at least one month of discontinuation of GH replacement ${ }^{3)}$. However, COGHD patients caused by organic brain lesions with three or more pituitary hormone deficiency do not require re-evaluation of GH status in transition period ${ }^{3)}$. In our cohort, $82.2 \%$ of patients had three or more pituitary hormone deficiency in addition to GHD, and all of them turned out to be adult GHD at re-evaluation.

There was no significant relationship between period of GH interruption and lipid profile or BMI in the present study. However, a deterioration of lipid profile, increased LDL/ HDL-cholesterol ratio has been reported in GHD adolescents after discontinuation GH therapy. Longer duration of GH interruption aggravated lipid profile ${ }^{11)}$. Meanwhile, serum IGF1 and IGFBP-3 levels were correlated with GH interruption period. Although normal IGF-1 levels do not exclude a diagnosis of GHD patients, IGF-1 and IGFBP-3 may represent helpful markers of GH secretary status.

Another challenge in adult GHD is to establish an optimal dose of GH replacement. Dose of GH therapy should be individualized to achieve normal serum IGF-1 levels ${ }^{5}$. The Endocrine Society recommended that a starting doses for patients aged 30-60 years and less than 30 years are 200-300 $\mu \mathrm{g} /$ day and $400-500 \mu \mathrm{g} /$ day, respectively $y^{5}$. Daily dosing should be increased by $100-200 \mu \mathrm{g}$ every 1 to 2 months ${ }^{5}$. Dose titration can be based on good clinical response, side effects, and subnormal range of IGF-1 levels ${ }^{11}$. The age at start of GH replacement for adult GHD was around 20 years, our patients received $440 \mu \mathrm{g} /$ day and they did not have any side effects of GH therapy.

In conclusion, this study showed improvement of lipid profile during GH replacement. Meanwhile, body weight and BMI were not affected by GH replacement. This study included a small number of patients and followed up patients with GHD for relatively short periods. Thus, long-term follow-up is needed to evaluate the efficacy of clinical and endocrine parameters.

\section{Conflict of interest}

No potential conflict of interest relevant to this article was 
reported.

\section{References}

1. Inzaghi E, Cianfarani S. The Challenge of Growth Hormone Deficiency Diagnosis and Treatment during the Transition from Puberty into Adulthood. Front Endocrinol (Lausanne) 2013;4:34.

2. Reed ML, Merriam GR, Kargi AY. Adult growth hormone deficiency - benefits, side effects, and risks of growth hormone replacement. Front Endocrinol (Lausanne) 2013;4:64.

3. Cook DM, Rose SR. A review of guidelines for use of growth hormone in pediatric and transition patients. Pituitary 2012;15:301-10.

4. Cook DM, Yuen KC, Biller BM, Kemp SF, Vance ML; American Association of Clinical Endocrinologists. American Association of Clinical Endocrinologists medical guidelines for clinical practice for growth hormone use in growth hormone-deficient adults and transition patients 2009 update. Endocr Pract 2009;15 Suppl 2:1-29.

5. Molitch ME, Clemmons DR, Malozowski S, Merriam GR, Vance ML; Endocrine Society. Evaluation and treatment of adult growth hormone deficiency: an Endocrine Society clinical practice guideline. J Clin Endocrinol Metab 2011;96:1587-609.

6. Duntas LH. Thyroid disease and lipids. Thyroid 2002; 12:287-93.
7. Maison P, Griffin S, Nicoue-Beglah M, Haddad N, Balkau B, Chanson P; Metaanalysis of Blinded, Randomized, PlaceboControlled Trials. Impact of growth hormone (GH) treatment on cardiovascular risk factors in GH-deficient adults: a Metaanalysis of Blinded, Randomized, PlaceboControlled Trials. J Clin Endocrinol Metab 2004;89:2192-9.

8. Ho KK; 2007 GH Deficiency Consensus Workshop Participants. Consensus guidelines for the diagnosis and treatment of adults with GH deficiency II: a statement of the GH Research Society in association with the European Society for Pediatric Endocrinology, Lawson Wilkins Society, European Society of Endocrinology, Japan Endocrine Society, and Endocrine Society of Australia. Eur J Endocrinol 2007;157:695-700.

9. Barake M, Klibanski A, Tritos NA. Effects of recombinant human growth hormone therapy on bone mineral density in adults with growth hormone deficiency: a meta-analysis. J Clin Endocrinol Metab 2014 Jan 1:jc20133921 [Epub]. http://dx.doi.org/10.1210/jc.2013-3921.

10. Kuzma M, Kuzmova Z, Zelinkova Z, Killinger Z, Vanuga P, Lazurova I, et al. Impact of the growth hormone replacement on bone status in growth hormone deficient adults. Growth Horm IGF Res 2014;24:22-8.

11. Kołtowska-Häggstrom M, Geffner ME, Jonsson P, Monson JP, Abs R, Hana V, et al. Discontinuation of growth hormone $(\mathrm{GH})$ treatment during the transition phase is an important factor determining the phenotype of young adults with nonidiopathic childhood-onset GH deficiency. J Clin Endocrinol Metab 2010;95:2646-54. 